\title{
Szanse i zagrożenia dla bezpieczeństwa i higieny pracy związane z wdrażaniem w przedsiębiorstwach technologii Przemysłu 4.0
}

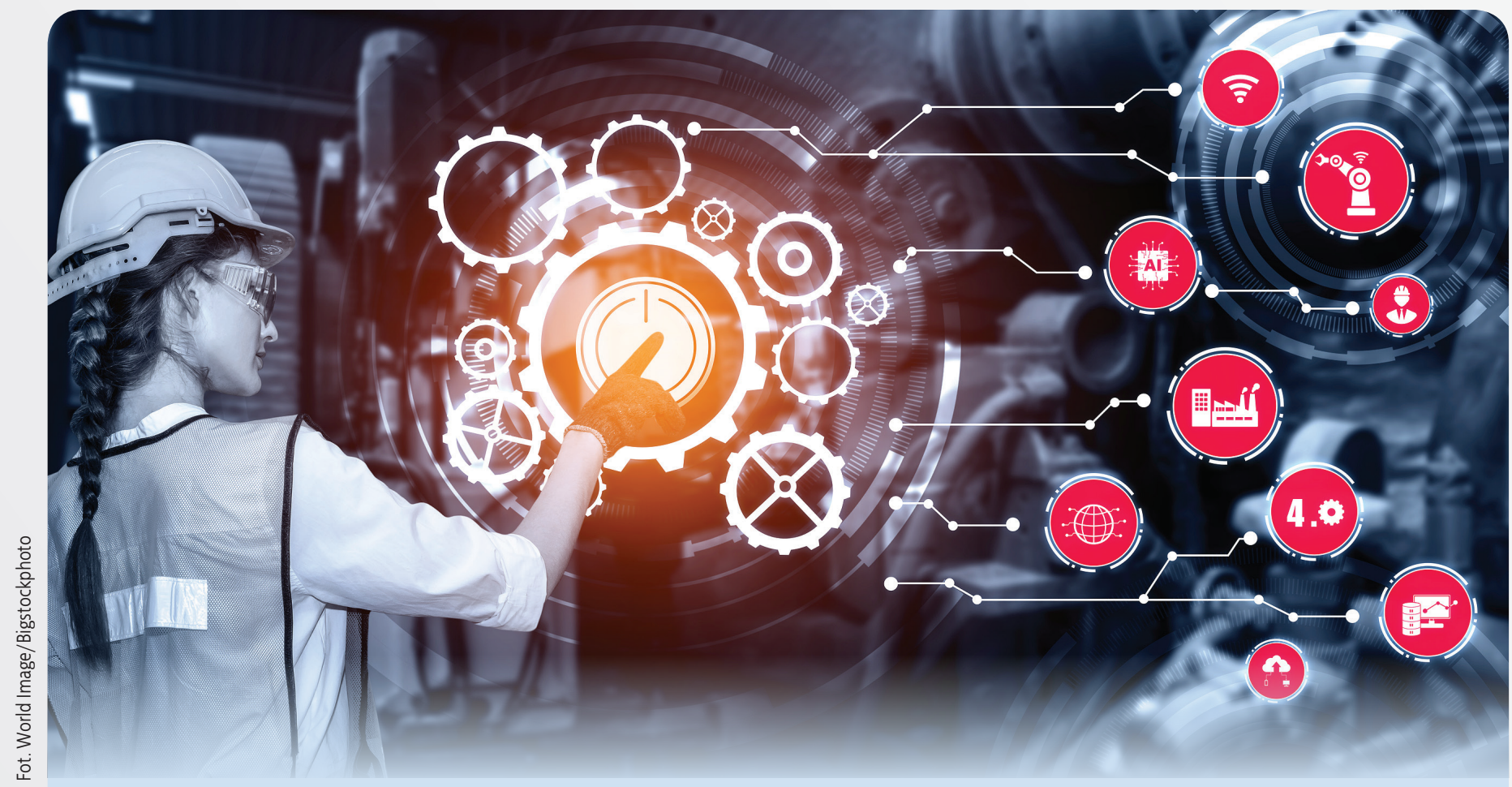

Wraz z wdrażaniem technologii Przemysłu 4.0 zmienia się środowisko pracy oraz powstają nowe szanse i zagrożenia dla bezpieczeństwa i higieny pracy. Są one związane zarówno z samymi technologiami, jak i ze zmianami w organizacji pracy oraz sposobem jej wykonywania. W artykule przedstawiono wyniki badania, przeprowadzonego wśród osób zajmujących się zagadnieniami bezpieczeństwa i ochrony zdrowia w pracy w celu pozyskania informacji na temat identyfikowanych przez nich czynników, które wpływają na bezpieczeństwo i zdrowie pracowników w przedsiębiorstwach wdrażających technologie i koncepcje produkcji w ramach Przemysłu 4.0.

Słowa kluczowe: Przemysł 4.0 a bezpieczeństwo i higiena pracy, zagrożenia dla bezpieczeństwa i zdrowia a technologie Przemysłu 4.0, szanse dla bezpieczeństwa i zdrowia a technologie Przemysłu 4.0

Opportunities and threats for occupational health and safety related to the implementation of Industry 4.0 technologies in enterprises As Industry 4.0 technologies are implemented, the work environment is changing and new opportunities and threats to occupational health and safety are arising. These are related both to the technologies themselves and to changes in the organization of work and the way it is carried out. The article presents the results of a survey conducted among people dealing with occupational safety and health issues in order to obtain information on the factors identified by them that affect the safety and health of employees in companies implementing technologies and production concepts within Industry 4.0.

Keywords: Industry 4.0 and occupational health and safety, safety and health risks and Industry 4.0 technologies, safety and health opportunities and Industry 4.0 technologies 


\section{Wstęp}

Obserwowane w ostatnich latach zmiany społeczne, przemysłowe i technologiczne, postępujące wraz z cyfrową transformacją przemysłu, nazywa się często czwartą rewolucją przemysłową lub Przemysłem 4.0. Na stronie internetowej Platformy Przemysłu Przyszłości Przemysł 4.0 jest definiowany jako „koncepcja opisująca złożony proces transformacji technologicznej i organizacyjnej przedsiębiorstw, który obejmuje integrację łańcucha wartości, wprowadzanie nowych modeli biznesowych oraz cyfryzację produktów i usług" [1]. Według badania pilotażowego GUS, przeprowadzonego w 2019 r., 58,3\% przedsiębiorstw (spośród 5515 objętych badaniem) wykorzystywało technologie Przemysłu 4.0, takie jak: Internet rzeczy (najwięcej wskazań), chmura obliczeniowa, Big Data czy sztuczna inteligencja [2].

Wraz z wdrażaniem technologii Przemysłu 4.0 zmienia się środowisko pracy oraz pojawiają się nowe szanse i zagrożenia dla bezpieczeństwa i higieny pracy. Są one związane z samymi technologiami oraz ze zmianami w organizacji pracy i sposobie jej wykonywania [3, 4]. Poprawę bezpieczeństwa i ochrony zdrowia pracujących można osiągnąć zarówno dzięki zastąpieniu ludzi przez roboty współpracujące przy wykonywa niu prac w warunkach szkodliwych dla zdrowia i uciążliwych (np. przy prostych i rutynowych zadaniach, które powodują zmęczenie, problemy z układem mięśniowo-szkieletowym, a także znudzenie powtarzalną pracą), jak i dzięki zasto sowaniu nowych technologii do monitorowania zagrożeń w środowisku pracy i samopoczucia pracowników (np. nagłych anomalii, takich jak upadek lub zmiany poziomu stresu) oraz stanu sprzętu, maszyn i urządzeń $[5,6]$. Wśród zagrożeń powstających w materialnym środowisku pracy i związanych ze stosowaniem nowych technologii najczęściej wymienia się możliwość awarii technicznych i błędów w oprogramowaniu oraz użytkowaniu robotów współpracujących, które mogą prowadzić do wypadków przy pracy [7]. Niekiedy zwraca się też uwagę, że tego typu technologie mogą stwarzać nie tylko zagrożenie wypadkami, lecz także zagrożenia elektryczne i termiczne, oraz powodować zwiększone narażenie na hałas, wibracje, promieniowanie i substancje chemiczne [8].

Zmiany w zakresie zadań realizowanych przez ludzi sprawiają, że zagrożenia w psychospołecznym środowisku pracy stają się bardziej widoczne niż zagrożenia fizyczne. Wśród tych zagrożeń wymienia się: przeciążenie psychiczne i intensyfikację pracy, wynikającą z niewłaściwej organizacji, utratę poczucia kontroli nad tempem, harmonogramem i sposobem wykonywania pracy, a także trudności z radzeniem sobie z problemami, siedzący tryb życia, zaburzoną równowagę między życiem zawodowym a prywatnym oraz związany z tym narastający stres psychospołeczny $[8,9]$. Ten stres może być wywołany również obawą o utratę pracy w związku z postępującą cy fryzacją i automatyzacją.

W artykule omówiono wyniki badania skierowanego na identyfikację szans i zagrożeń dla bezpieczeństwa i higieny pracy, związanych z wykorzystywaniem technologii Przemysłu 4.0 w przedsiębiorstwach produkcyjnych. Badanie przeprowadzono wśród osób zaangażowanych w zarządzanie bezpieczeństwem i higieną pracy w tych firmach.

\section{Metoda badania}

W celu pozyskania informacji na temat czynników, które zdaniem osób zajmujących się zagadnieniami bezpieczeństwa i ochrony zdrowia (specjalistów ds. bhp oraz osób odpowiedzialnych za wdrażanie systemów zarządzania bhp w przedsiębiorstwach) w największym stopniu wpływają na bezpieczeństwo izdrowie pracowników w przedsiębiorstwach wdrażających technologie i koncepcje produkcji w ramach Przemysłu 4.0, przeprowadzono badania kwestionariuszowe. Kwestionariusz badawczy zawierał pytania odnoszące się do wymienianych w literaturze potencjalnych czynników zagrożeń i szans związanych z wdrażaniem nowych technologii, $w$ tym pytania dotyczące:

- czynników wpływających na bezpieczeństwo i ochronę zdrowia osób pracujących w sąsiedztwie robotów współpracujących i/lub pojazdów samojezdnych

- uciążliwości związanych ze zdalnym sterowaniem robotami i maszynami

- wpływu wdrażania technologii Przemysłu 4.0 na czynniki kształtujące psychospołeczne środowisko pracy oraz oddziałujące na zdrowie i samopoczucie pracowników

- szans i zagrożeń związanych z wykorzystywaniem technologii Przemysłu 4.0 do monitorowania środowiska pracy.

AWARIE ROBOTÓW I POJAZDÓW SAMOJEZDNYCH, KTÓRE MOGĄ BYĆ PRZYCZYNĄ KOLIZJI POWODUJĄCYCH URAZY

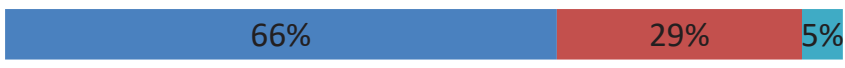

BŁĘDY PODCZAS OBSŁUGI NARZĘDZI PRZEZ ROBOTY WSPÓŁPRACUJĄCE, KTÓRE MOGA PROWADZIĆ DO WYPADKÓW

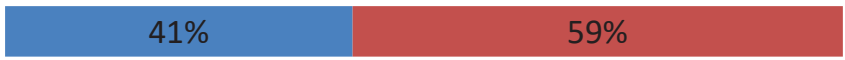

NIERUTYNOWE DZIAŁANIA PODCZAS KONSERWACJI ROBOTÓW I POJAZDÓW SAMOJEZDNYCH, KTÓRE MOGĄ PROWADZIĆ DO WYPADKÓW

DRGANIA, KTÓRE DZIAŁAJĄ NA CAŁE CIAŁO

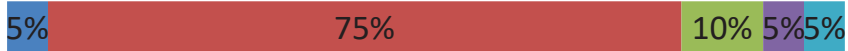

HAŁAS, KTÓRY MOŻE POWODOWAĆ USZKODZENIE SŁUCHU

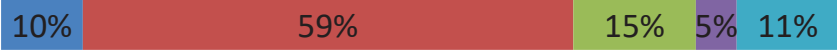

HAŁAS UCIĄŻLIWY, KTÓRY PRZESZKADZA W PRACY

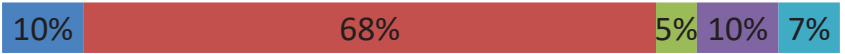

POLE ELEKTROMAGNETYCZNE

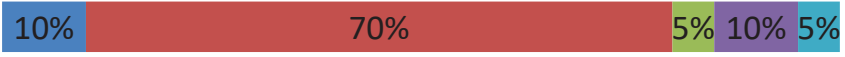

Rys. 1. Oceny znaczenia różnych czynników dla bezpieczeństwa i ochrony zdrowia osób wykonujących pracę w sąsiedztwie robotów współpracujących i/lub pojazdów samojezdnych (procent odpowiedzi)

Fig. 1. Evaluations of the importance of various factors for the safety and health of people working in the vicinity of collaborative robots and/or self-driving vehicles (percentage of responses) 
WYKONYWANIE CZYNNOŚCI WYMAGAJACYCH DOKŁADNOŚCI I KONCENTRACJI

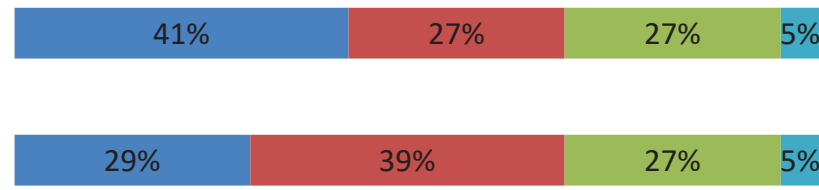

POZOSTAWANIE W POZYCJI SIEDZĄCEJ

WYKONYWANIE POWTARZALNYCH RUCHÓW RĘKI LUB RAMIENIA
$22 \%$ $44 \%$

WYKONYWANIE MONOTONNYCH CZYNNOŚCI

WYKONYWANIE CZYNNOŚCI Z BARDZO DUŻĄ PRĘDKOŚCIĄ

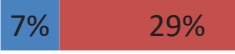

$29 \%$

- ZAWSZE/PRAWIE ZAWSZE

Rys. 2. Oceny uciążliwości związanych ze zdalnym sterowaniem robotami i maszynami (procent odpowiedzi)

Fig. 2. Evaluation of burden associated with remote control of robots and machines (percentage of responses)

OGRANICZA INICJATYWĘ I KREATYWNOŚĆ PRACOWNIKÓW

UNIEMOŻLIWIA WYBÓR LUB ZMIANĘ CZASU PRZERWY W PRACY

UNIEMOŻLIWIA WYBÓR LUB ZMIANĘ SPOSOBU WYKONYWANIA SWOJEJ PRACY

WPŁYWA NA ZWIĘKSZENIE INTENSYWNOŚCI PRACY

WPŁYWA NA ZMNIEJSZENIE ODCZUWANEGO POZIOMU WSPARCIA ZE STRONY PRZEŁOŻONYCH

UTRUDNIA KOMUNIKOWANIE SIĘ PRACOWNIKÓW Z PRZEŁOŻONYMI

WPŁYWA NA ZMNIEJSZENIE ODCZUWANEGO POZIOMU WSPARCIA ZE STRONY WSPÓŁPRACOWNIKÓW

UTRUDNIA KOMUNIKOWANIE SIĘ MIĘDZY PRACOWNIKAMI
$29 \%$ $39 \%$

$20 \%$

$34 \%$

$39 \%$

$5 \% \quad 17 \% \quad 5 \%$

$32 \%$

$41 \%$

$15 \% \quad 7 \% 5 \%$

$39 \%$

$34 \%$

$15 \% \quad 7 \% 5 \%$

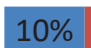

$38 \%$

$30 \%$

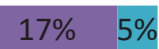

$10 \%$

$34 \%$

$34 \%$

$17 \% \quad 5 \%$

$\begin{array}{lllll}20 \% & 37 \% & 23 \% & 15 \% & 5 \%\end{array}$

\section{$15 \%$}

Rys. 3. Oceny wpływu współpracy ludzi z robotami na wybrane aspekty psychospołecznego środowiska pracy (procent odpowiedzi)

Fig. 3. Evaluations of the impact of human-robot collaboration on selected aspects of the psychosocial working environment (percentage of responses)

Kwestionariusz badawczy przygotowano w wersji elektronicznej i papierowej jako kwestionariusz wywiadu. Badania przeprowadzono na przełomie sierpnia i września 2021 r. wśród 41 osób, z których 20 wypełniło kwestionariusz w wersji elektronicznej, a 21 uczestniczyło w wywiadach telefonicznych. Większość badanych (26 osób) reprezentowała przedsiębiorstwa wdrażające technologie Przemysłu 4.0, a 15 - przedsiębiorstwa niewdrażające takich technologii.

\section{Wyniki badania}

Ocena wpływu różnych czynników na bezpieczeństwo i ochronę zdrowia osób pracujących w sąsiedztwie robotów wspótpracujacych i/lub pojazdów samojezdnych

Potencjalny wpływ różnych czynników na bezpieczeństwo i ochronę zdrowia osób pracujących w sąsiedztwie robotów współpracujących i/lub pojazdów samojezdnych oceniano, uznając określony czynnik za bardzo ważny, ważny, mało ważnylub catkiem nieważny; w razie wątpliwości można było wybrać odpowiedź nie mam zdania. Oceny osób uczestniczących w badaniu ilustruje rys. 1. Jako bardzo ważne badani wskazywali najczęściej te zagrożenia, które mogą powodo wać wypadki przy pracy i są związane z awariami technicznymi robotów (ten pogląd wyraziło $66 \%$ osób uczestniczących w badaniu), a także z ich konserwacją oraz błędami w ich pracy. Nieco niżej oceniono niekorzystne oddziaływanie czynników 
WPROWADZANIE ROBOTYZACJI I CYFRYZACJI SPOWODUJE KONIECZNOŚĆ ZWALNIANIA OSÓB O NISKICH KWALIFIKACJACH

WPROWADZANIE ROBOTYZACJI I CYFRYZACI ZNACZNIE ZWIECKSZA STRES ZWIĄZANY Z MOŻLIWOŚCIĄ UTRATY PRACY

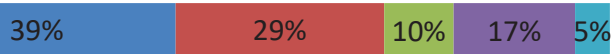

WPROWADZANIE ROBOTYZACJI I CYFRYZACJI WYMAGA CIAGŁYCH SZKOLEN W CELU PODNOSZENIA KWALIFIKACJI PRACOWNIKÓW

ZASTOSOWANIE SZTUCZNEJ INTELIGENCII POWODUJE U PRACOWNIKA POCZUCIE BRAKU KONTROLI NAD PROCESEM PRACY

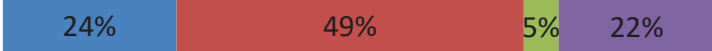

PRACUJACY W OTOCZENIU ROBOTÓW WSPÓłPRACUJACYCH I POJAZDÓW SAMOJEZDNYCH RZADZIEJ NIŻ INNI PRACUJĄCY BĘDA MOGLI I CHCIELI WYKONYWAĆ SWOJĄ PRACĘ DO WIEKU EMERYTALNEGO

\begin{tabular}{|c|}
\hline $20 \%$ \\
\hline
\end{tabular}

PRACA W OTOCZENIU ROBOTÓW WSPÓŁPRACUJĄCYCH I POJAZDÓW SAMOJEZDNYCH WPŁYWA NIEKORZYSTNIE NA STAN ZDROWIA

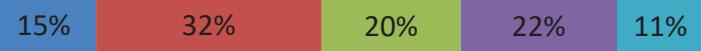

PRACA W OTOCZENIU ROBOTÓW WSPÓŁPRACUJĄCYCH I POJAZDÓW SAMOJEZDNYCH WPŁYWA NIEKORZYSTNIE NA SAMOPOCZUCIE PSYCHICZNE

\begin{tabular}{|c|c|}
\hline $15 \%$ & $37 \%$ \\
\hline
\end{tabular}

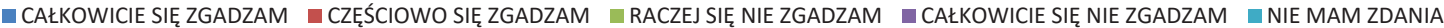

Rys. 4. Oceny wpływu współpracy ludzi z robotami na wybrane aspekty życia zawodowego (procent odpowiedzi)

Fig. 4. Evaluations of the impact of human-robot collaboration on selected aspects of working life (percentage of responses) szkodliwych związanych z pracą robotów, takich jak drgania, hałas czy pola elektromagnetyczne (na ogół nie wskazywano ich jako bardzo ważne)

\section{Ocena uciążliwości związanych ze zdalnym sterowaniem robotami i maszynami}

Wśród uciążliwości związanych ze zdalnym sterowaniem robotami i maszynami najczęściej wskazywano na potrzebę dokładności i koncentracji (41\% odpowiedzi zawsze/prawie zawsze) inieco rzadziej na konieczność pozostawania w pozycji siedzącej (29\% odpowiedzi zawsze/prawie zawsze). Ponad $60 \%$ badanych uznało, że oba te czynniki mogą być istotne - zawsze lub czasami - w procesach zdalnego sterowania maszynami i robotami, podobnie jak wykonywanie powtarzalnych ruchów. Mniej niż $60 \%$ wskazało na występowanie monotonii w tego rodzaju pracy, przy czym tylko 22\% sądzi, że prawie zawsze towarzyszy ona procesom sterowania. Większość badanych nie identyfikuje konieczności wykonywania zadań z dużą prędkością jako czynnika, który może w dużym stopniu wpływać na bezpieczeństwo i ochronę zdrowia przy tego rodzaju pracach (rys. 2.).

\section{Ocena wpływu współpracy ludzi} z robotami na wybrane aspekty psychospołecznego środowiska pracy

$A z ̇ 73 \%$ respondentów zgodziło się z poglą dem (całkowicie lub w części), że współpraca ludzi z robotami uniemożliwia zmianę sposobu wyko nywania pracy i wyboru czasu przerw oraz wpływa na zwiększenie intensywności pracy, a 69\% przyznało, że może ona też ograniczać inicjatywę i kreatywność pracowników. Opinie na temat wpływu współpracy z robotami na wsparcie i ko munikowanie się w pracy były podzielone: tylko nieco ponad połowa badanych zgodziła się (całkowicie lub w części), że współpraca ludzi z robotami spowoduje zmniejszenie odczuwanego wsparcia ze strony współpracowników i utrudni komunikację między pracownikami, a nieco mniej niż połowa - że wpłynie również na zmniejszenie odczuwanego wsparcia ze strony przełożonych i utrudni komunikację z nimi (rys. 3.).

\section{Wpływ wdrażania technologii \\ Przemysłu 4.0 na wybrane aspekty życia zawodowego}

Ponad połowa (59\%) ankietowanych zgodziła się (w pełni lub częściowo) ze stwierdzeniem, że jednym z następstw postępującej automatyzacji i cyfryzacji (w efekcie wdrażania technologii Przemysłu 4.0) będzie zwalnianie z pracy osób o niskich kwalifikacjach, a $68 \%$ respondentów wyraziło obawę, że automatyzacja i cyfryzacja mogą wpływać na zwiększenie stresu związanego z utrata pracy. Istotnym czynnikiem mogącym potęgować ten stres jest również odczuwany przez pracownika brak kontroli nad procesami pracy, identyfikowany przez $73 \%$ uczestników badania. Opinie na temat wpływu pracy w otoczeniu robotów i pojazdów samojezdnych na zdrowie fizyczne i samopoczucie psychiczne były podzielone, chociaż 61\% osób zgodziło się (w pełni lub częściowo) ze stwierdzeniem, że pracujący w otoczeniu robotów i pojazdów samojezdnych rzadziej niż inni będą mogli i zechcą wykonywać swoją pracę do wieku emerytalnego (rys. 4.).

\section{Szanse i zagrożenia dla bezpieczeństwa i ochrony zdrowia zwiazane z wykorzystywaniem technologii Przemysłu 4.0 do monitorowania środowiska pracy}

Niemal wszyscy uczestnicy badania zgodzili się z poglądem, że zastosowanie technologii Przemysłu 4.0 pozwoli wyeliminować prace stwarzające duże zagrożenie dla pracowników i zapewni lepszą ochronę zdrowia w pracy dzięki monitorowaniu związanych z nią zagrożeń. Jednocześnie zdaniem $76 \%$ respondentów stosowanie czujników do monitorowania i sygnalizowania zagrożeń może wpływać na zmniejszenie świadomości tych zagrożeń wśród pracowników, a 32\% uznało, że monitorowanie funkcjonowania i stanu zdrowia pracowników nie będzie dla nich źródłem dodatkowego stresu w pracy (rys. 5.).

\section{Podsumowanie}

Opinie osób uczestniczących w badaniu potwierdzają, że wdrażanie technologii Przemysłu 4.0 stwarza nowe szanse na poprawę bezpieczeństwa i ochrony zdrowia. Chodzi przede wszystkim o możliwość wyeliminowania pracy w warunkach 


\begin{abstract}
ZASTOSOWANIE ROBOTÓW WSPÓŁPRACUJĄCYCH I EGZOSZKIELETÓW UMOŻLIWI WYELIMINOWANIE PRAC STWARZAJĄCYCH DUŻE ZAGROŻENIA DLA ZDROWIA PRACOWNIKA
\end{abstract}

INTELIGENTNE ŚRODKI OCHRONY INDYWIDUALNEJ Z WBUDOWANYMI CZUJNIKAMI DO MONITOROWANIA ZAGROŻEŃ ZAPEWNIA PRACOWNIKOM LEPSZĄ OCHRONE

STOSOWANIE CZUJNIKÓW DO MONITOROWANIA I SYGNALIZOWANIA ZAGROŻEŃ WPŁYNIE NA ZMNIEJSZENIE ŚWIADOMOŚCI TYCH ZAGROŻEŃ WŚRÓD PRACOWNIKÓW

INTELIGENTNE ŚRODKI OCHRONY INDYWIDUALNEJ Z WBUDOWANYM CZUJNIKAMI DO MONITOROWANIA DZIAŁAŃ PRACOWNIKÓW I ICH PARAMETRÓW ŻYCIOWYCH BĘDA ŹRÓDŁEM DODATKOWEGO STRESU
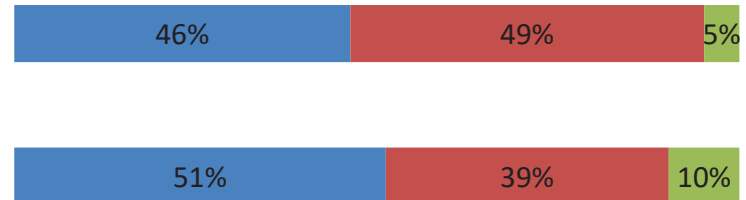

$10 \%$
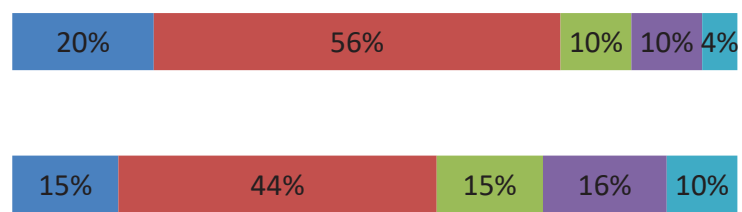

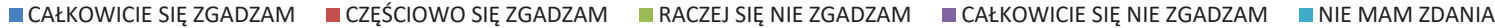

Rys. 5. Ocena szans i zagrożeń związanych z wykorzystywaniem technologii Przemysłu 4.0 do wspomagania prac stwarzających duże zagrożenia dla zdrowia oraz monitorowania środowiska pracy (procent odpowiedzi)

Fig. 5. Evaluations of opportunities and risks of using Industry 4.0 technologies to support work with high health risks and to monitor the working environment (percentage of responses)

narażenia na szkodliwe czynniki środowiska pracy lub na dolegliwości układu mięśniowo-szkieletowego oraz o możliwość ciągłego monitorowania zagrożeń w środowisku pracy i funkcjonowania pracowników. Równocześnie powstają nowe zagrożenia - zarówno w materialnym, jak i psychospołecznym środowisku pracy. Problemem najczęściej identyfikowanym przez badanych jest niezawodność rozwiązań technicznych, gdyż awarie i błędy w oprogramowaniu mogą prowadzić do wypadków. Należy jednak podkreślić, że liczba wypadków powodowanych przez roboty jest niewielka, co pozwala wnioskować, że ich wykorzystanie przyczynia się z dużym prawdopodobieństwem do zmniejszenia liczby wypadków [10]. Wśród uciążliwości związanych ze zdalnym sterowaniem robotami wskazywano głównie na potrzebę dokładności i koncentracji.

Wśród czynników narastających w psycho społecznym środowisku pracy do najczęściej identyfikowanych należą: brak możliwości zmiany sposobu wykonywania pracy i wyboru czasu przerw oraz zwiększenie intensywności pracy, a także ograniczenie inicjatywy i kreatywności pracowników. Monitorowanie funkcjonowania pracowników, którego podstawowym celem jest wczesne wykrywanie zagrożeń, może być również źródłem dodatkowego stresu. Można jednak zauważyć, że znacznie większy procent badanych wyraża pewność co do korzyści wynikających z monitorowania zagrożeń z wykorzystaniem nowych technologii niż obawę dotyczącą występowania stresu związanego z wprowadzaniem takich rozwiązań. Wynika to niewątpliwie z potwierdzonego badaniami faktu, że występowanie tych czynników i ich oddziaływanie na ludzi zależy w dużym stopniu od sposobu wprowadzania nowych technologii [11].

Za istotne zagrożenie związane $z$ wdrażaniem technologii Przemysłu 4.0 można uznać niepewność zatrudnienia i związany z nią stres - ponad połowa uczestników badania podziela powszechnie wyrażaną w literaturze opinię, że jednym z następstw postępującej automatyzacji i cyfryzacji będzie zwalnianie z pracy osób o niskich kwalifikacjach, niemal 70\% uważa, że procesy robotyzacji i cyfryzacji znacznie zwiększą stres związany z możliwością utraty zatrudnienia, a nieco więcej jest zdania, że ich wprowadzanie wymaga ciagłych szkoleń w celu podnoszenia kwalifikacji personelu.

\section{BIBLIOGRAFIA}

[1] https://przemyslprzyszlosci.gov.pl (dostęp: 25.09.2021).

[2] Centrum Badań i Edukacji Statystycznej GUS Wypracowanie metodologii oraz badanie stopnia dostosowania wybranych przedsiębiorstw do wymogów gospodarczych, jakie stawia czwarta fala rewolucji przemysłowej (Przemysł 4.0). Warszawa: GUS, 2020. https://stat.gov.pl/ statystyki-eksperymentalne/badania-i-rozwojinnowacyjnosc-spoleczenstwo-informacyjne/ wypracowanie-metodologii-oraz-badanie-stopniadostosowania-wybranych-przedsiebiorstw-dowymogow-gospodarczych-jakie-stawia-czwartafala-rewolucji-przemyslowej-przemysl-4-0,13,1. html.

[3] Eurofound. Game-changing technologies: Transforming production and employment in Europe. Luxembourg: Publications Office of the European Union, 2020. https://www.eurofound europa.eu/sites/default/files/ef_publication/ field_ef_document/ef19047en.pdf.

[4] BADRI, A., BOUDREAU-TRUDEL, B., SOUISSI, A.S. Occupational health and safety in the industry 4.0 era: A cause for major concern? Safety Science. 2018, 109: 403-411, doi: 10.1016/j.ssci.2018.06.012.

[5] EU-OSHA-European Agency for Safety and Health at Work. Monitoring technology: the $21^{\text {st }}$ century's pursuit of well-being? 2017. https:// osha.europa.eu/en/tools-and-publications/ publications/monitoring-technology-workplace/ view.

[6] PODGÓRSKI, D., et al. Towards a conceptual framework of OSH risk management in smart working environments based on smart PPE, ambient intelligence and the Internet of Things technologies. International Journal of Occupational Safety and Ergonomics. 2017, 23(1): 1-20, doi: 10.1080/10803548.2016.1214431.

[7] VASIC, M., BILLARD, A. Safety Issues in Human-Robot Interactions. 2013 IEEE International Conference on Robotics and Automation, 2013, pp. 197-204, doi: 10.1109/ICRA.2013.6630576.

[8] MURASHOV, V., HEARL, F., HOWARD, J. Working safety with robot workers: recommendations for the new workplace. Journal of Occupational and Environmental Hygiene. 2016, 13(3): D61-71, doi: 10.1080/15459624.2015.1116700.

[9] LESO, V., FONTANA, L., IAVICOLI, I. The occupational health and safety dimension of Industry 4.0. Med Lav. 2018; 109(5): 327-338, October 2018La Medicina del lavoro. 2018, 110(5): 327-338, doi: $10.23749 / \mathrm{mdl} . v 110 i 5.7282$

[10] MOORE, P.V. Artificial Intelligence: Occupational Safety and Health and the Future of Work EU-OSHA 2019, https://osha.europa.eu/ en/publications/osh-and-future-work-benefitsand-risks-artificial-intelligence-tools-workplaces/ view.

[11] VOGL, G.W., WEISS, B.A., HELU, M. A review of diagnostic and prognostic capabilities and best practices for manufacturing. Journal of Intelligent Manufacturing. 2019, 30: 79-95, doi: 10.1007/ s10845-016-1228-8.

Publikacja opracowana na podstawie wyników $\checkmark$ etapu programu wieloletniego "Poprawa bezpieczeństwa i warunków pracy", finansowanego w latach 2021-2022 w zakresie zadań służb państwowych ze środków ministra właściwego ds. pracy.

Koordynator programu: Centralny Instytut Ochrony Pracy - Państwowy Instytut Badawczy. 